San Jose State University

SJSU ScholarWorks

\title{
$5-2018$
}

\section{Improving Teen and Pediatric Provider Communication through Education and Technology}

Kathy A. Connor-Prows

California State University, Northern California Consortium Doctor of Nursing Practice

Follow this and additional works at: https://scholarworks.sjsu.edu/etd_doctoral

Part of the Pediatric Nursing Commons

\section{Recommended Citation}

Connor-Prows, Kathy A., "Improving Teen and Pediatric Provider Communication through Education and Technology" (2018). Doctoral Projects. 89.

DOI: https://doi.org/10.31979/etd.u85s-yvg8

https://scholarworks.sjsu.edu/etd_doctoral/89

This Doctoral Project is brought to you for free and open access by the Master's Theses and Graduate Research at SJSU ScholarWorks. It has been accepted for inclusion in Doctoral Projects by an authorized administrator of SJSU ScholarWorks. For more information, please contact scholarworks@sjsu.edu. 


\section{ABSTRACT \\ IMPROVING TEEN AND PEDIATRIC PROVIDER COMMUNICATION THROUGH EDUCATION AND TECHNOLOGY}

Navigating healthcare can be daunting as an adult, but doing so as a teenager can seem virtually impossible. Until the age of eighteen, parents of children of all ages initiate, schedule, and accompany their children to see their pediatrician for virtually all appointments. Over time, children and their parents develop a special bond with their pediatrician and too frequently, this relationship becomes abruptly severed as their teen turns eighteen years old and is thrust into adult medicine. As healthcare providers, we expect healthcare consumers (including teens) to know how and when to initiate, schedule, and get themselves to an appointment. This expectation is unrealistic. Without knowing how to access their own healthcare, teens often fail. If transitioning teens lack the education and confidence, to navigate their own healthcare, their short-term and long-term outcomes can potentially be both costly and unpleasant (Haggerty, et. al 2006). Healthcare providers need to take an active role to embrace teens and help them take responsibility for their health care as they move from pediatric to adult medicine. Will the introduction of education and technology improve the online connection between teens before they transition to adult medicine? If health care providers or their representatives introduce teens to healthcare technology will the teens interact with their pediatric provider?

Kathy A. Connor-Prows

May 2018 



\title{
IMPROVING TEEN AND PEDIATRIC PROVIDER COMMUNICATION THROUGH EDUCATION AND TECHNOLOGY
}

by
Kathy A. Connor-Prows MSN, RN, FNP, DNP(c)

\author{
A project \\ submitted in partial \\ fulfillment of the requirements for the degree of \\ Doctor of Nursing Practice \\ California State University, Northern Consortium \\ Doctor of Nursing Practice
}

May 2018 


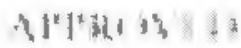

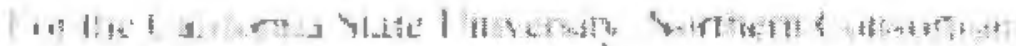

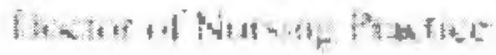

4h. $\ln$ iant

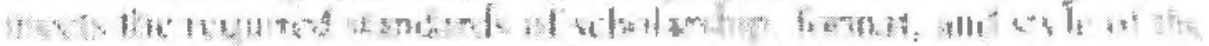
In

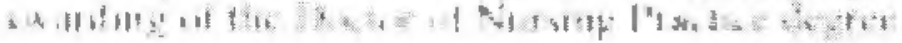

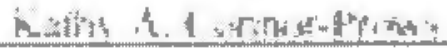

PTotjex: nuther

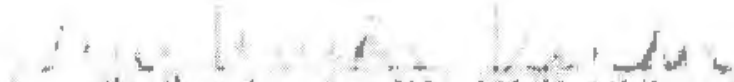

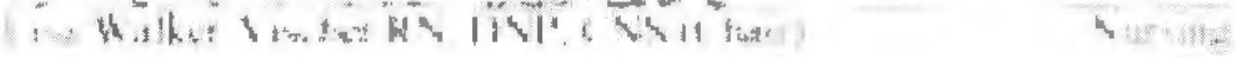

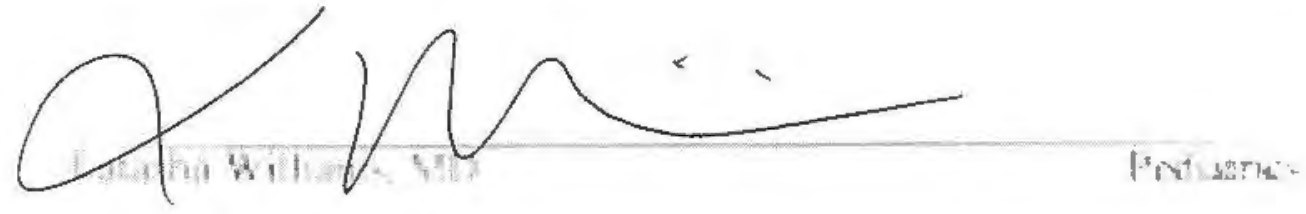

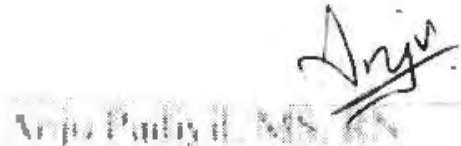

Jessue Protugtims 


\section{AUTHORIZATION FOR REPRODUCTION}

\section{OF DOCTORAL PROJECT}
$\mathrm{X} \quad \mathrm{I}$ grant permission for the reproduction of this project in part or in its entirety without further authorization from me, on the condition that the person or agency requesting reproduction absorbs the cost and provides proper acknowledgment of authorship.

Permission to reproduce this project in part or in its entirety must be obtained from me.

Signature of project author:

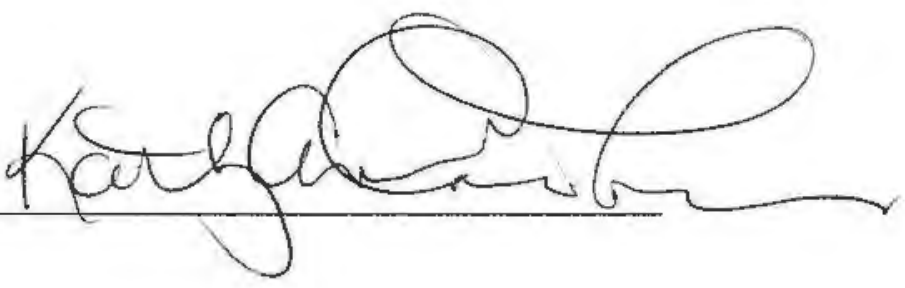




\section{ACKNOWLEDGMENTS}

Ruth Rosenblum, DNP, RN, PNP-BC, CNS Chairperson/Advisor

Lisa Walker-Vischer, RN, DNP, CNS Chairperson

Latasha Williams, MD Physician, Santa Clara Kaiser Permanente

Anju Padiyil, MS, RN Santa Clara Kaiser Permanente Pediatrics

Quang Dao, MD Chief, Santa Clara Kaiser Permanente Pediatrics

Santa Clara Kaiser Permanente Pediatric Department, all employees. 


\section{TABLE OF CONTENTS}

Page

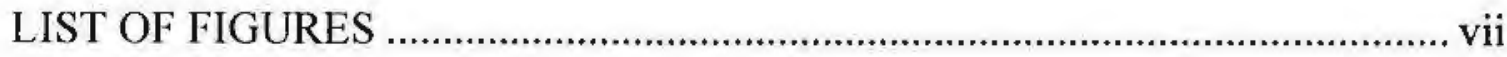

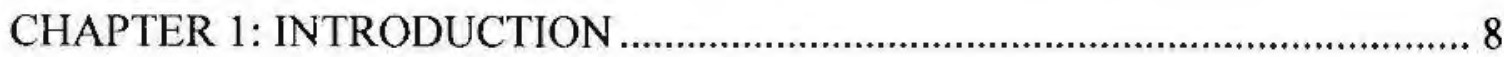

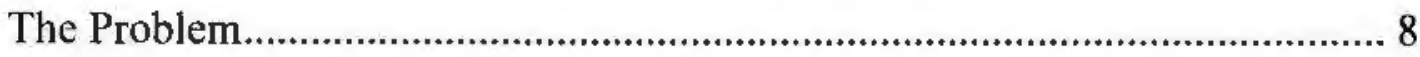

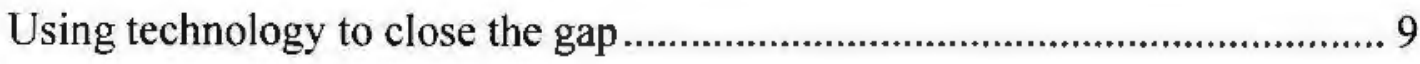

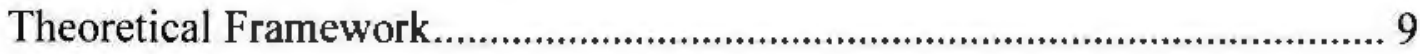

CHAPTER 2: REVIEW OF LITERATURE ……............................................ 11

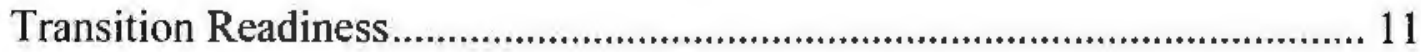

Healthcare Communication ........................................................................ 13

Summary of Literature Review ............................................................... 15

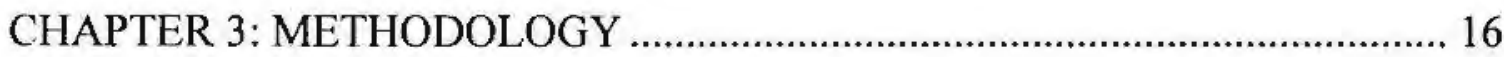

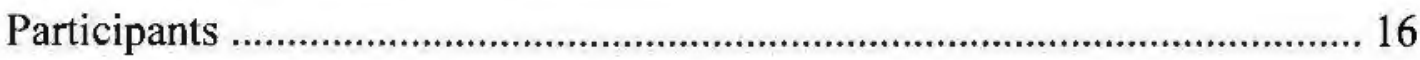

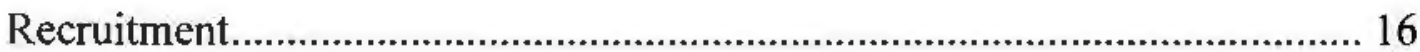

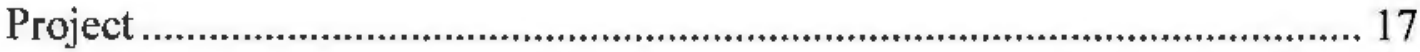

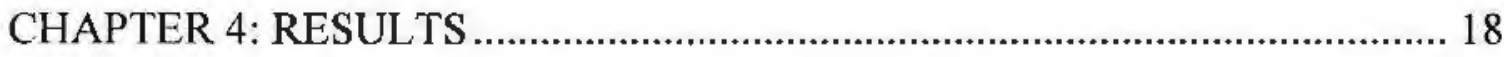

CHAPTER 5: CONCLUSIONS AND RECOMMENDATIONS......................... 21

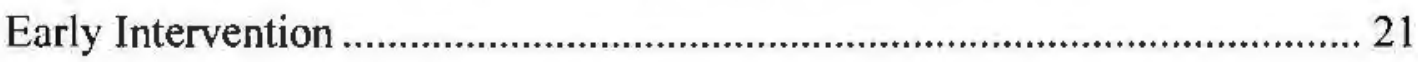

Condensing Educational Component …………….......................................... 21

Provider Driven Communication................................................................... 22

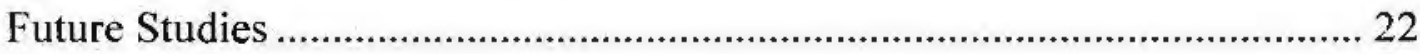

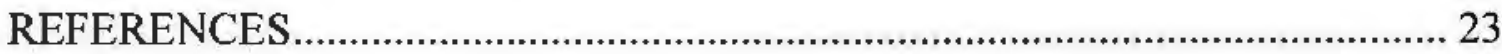

APPENDICES …

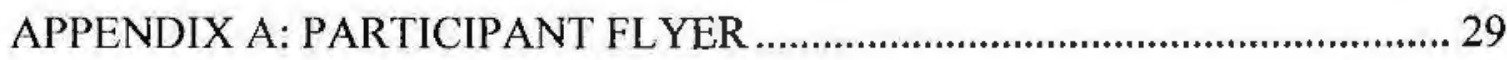

APPENDIX B: PARTICIPANT EMAIL \#1 ...................................................... 31 


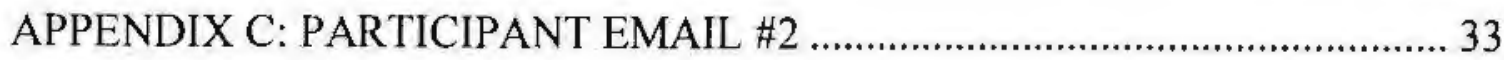

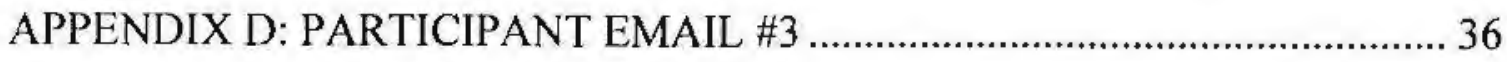

APPENDIX E: PARTICIPANT EMAIL \#4_................................................... 39

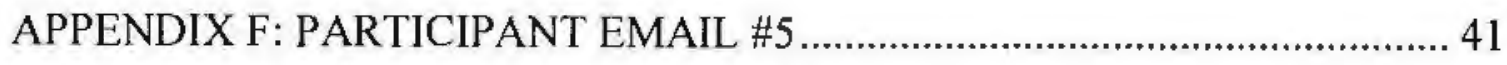

APPENDIX G: INSTITUTIONAL REVIEW BOARD APPROVALS ................ 43

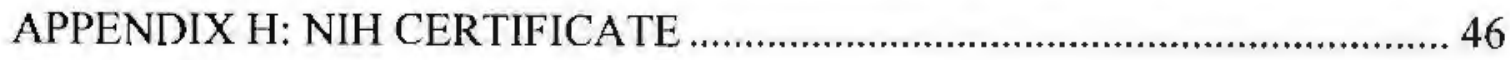




\section{LIST OF FIGURES}

Page

Figure 1. Project participation by gender ..................................................... 18

Figure 2. Initial survey for confidence. ............................................................ 19

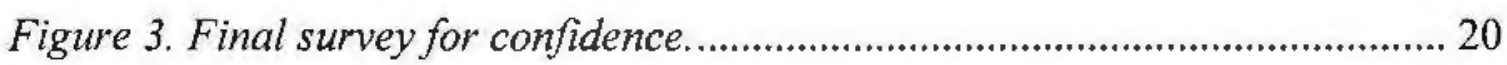




\section{CHAPTER 1: INTRODUCTION}

Engaging teens with their pediatric providers is often difficult because, as under utilizers of healthcare, well teens visit their pediatrician one-third as often as younger pediatric patients and children with chronic diseases (Yonkers, 2015).

Under utilizers who infrequently visit health care providers, are often less immunized, have less basic health screenings completed and are not prepared to enter the world of adult medicine. Historically, teens without chronic mental or physical conditions are considered under utilizers and, as a group, visit the doctor half as often as other age groups (Beal, Nye, Marraccini, \& Biro, 2014), making it difficult to engage them with their provider and assure that their preventative health measures are current.

\section{The Problem}

Parents have full access to their children's electronic medical record (EMR) until the age of 12. Health Insurance Portability and Privacy Act (HIPPA) regulations limit parental access to the child's EMR between the ages of 12 to 18 . Once the teen turns 18 years of age, parental access to any EMR information is completely deactivated. Once this transpires, health care providers are often left with only parental demographic information in the teens EMR. HIPPA prevents health care workers from contacting family members once the teen turns 18 years old. If the teen's phone number is not in their EMR prior to turning 18, their new provider of adult medicine has no way to contact them and must wait until the teen initiates the connection. The essential task is helping teens connect with their health care provider electronically prior to their 18 th birthday. Failing to make this critically timed connection leaves many teens disconnected to health care services even though they are insured. If teens lack the confidence, or perceived confidence 
to navigate their own healthcare, their short-term and long-term outcomes can potentially be both costly and unpleasant. Preventative health measures such as blood pressure, body mass index (BMI) that are routinely monitored will be forgone and adverse sequelae may eventually ensue.

Currently, only one-third of the 5,537 17-year-olds in a large pediatric clinic at a Health Maintenance Organization (HMO) in Northern California, are connected to their pediatric provider through the organization's email system (Kaiser, 2017). Demographic information in a pediatric patient's electronic medical record (EMR) is that of their parents. The problem is that if the teen's own contact information is not entered in to their EMR prior to their 18th birthday, adult medicine providers are left without any way to contact to their new patient, and must wait until the teen reaches out to them.

\section{Using technology to close the gap}

Having grown up in a technology fed society, today's teens have mastered social media, emailing, texting, and video conferencing within their personal life. As providers, we should utilize their technological prowess to help reduce the gap in care between pediatrics and adult medicine. The research question in this quality improvement (QI) project is, will the use of technology and education improve communication between pediatric providers and the teens they care for? This project served to attempt to utilize current technology to connect teen patients with their pediatric providers prior to the transition to adult medicine and increase their confidence in booking an appointment and communicating with any health care provider.

\section{Theoretical Framework}

Braungart and Braungart, 2011, states "Social cognitive model provides a valuable public health tool for societal efforts to promote the health of its youth". 
Because physically well, teens often perceive their healthcare needs as less than important, health care providers and parents serve as observational models in this project for teens as they transition to adult medicine and assume responsibility for their health and well-being. Through individual instruction, teens in this project were asked to achieve an end goal. Self-regulation determined if they reached that goal and for those that did, reinforcement was provided by healthcare providers.

Albert Bandura's Social Cognition Theory (SCT) is based on the premise that people learn through imitating, observing and modeling. Key components of this theory are: learning by observation, goal-directing, self-regulation, and reinforcement. Learning through observation can include both live and non-living (inanimate models). Living models include peers, parents, teachers, health care providers while inanimate models include: movies, lesson plans, and technology. In SCT, goal setting is the foundation of modeling through observation. The accomplishment of clear goals is the result of learning. Self-regulation factors into SCT as the learner determines if they will use what is learned and achieve an end goal or not. Reinforcement to learners in SCT can be anything the individual deems important to continue learning. 


\section{CHAPTER 2: REVIEW OF LITERATURE}

\section{Emerging Adults}

Arnett (2003) identified numerous societal changes that have contributed to the lengthening the transition from teens to adulthood. Importance of college education including graduate degrees, later entrance into marriage, later childbearing, and struggles for financial independence are just factors in this change. He has labeled this period as a transition and the individuals within "emerging adults" (late adolescences through the late twenties). In 300 interviews, Amett found the following characteristics of emerging adults: identity explorations, instability, self-focus, feeling in-between, and possibilities or optimism (2003). These characteristics, along with evolving societal environments lead people in this age group to develop issues in areas of finance, independence, relationships, responsibilities, and health care. Health care issues in emerging adults include mental health, dental, and increased use of emergency services.

Aldiss et al., (2015) conducted a qualitative, multi-site, multi-staged study to identify core aspects of difficulties transitioning teens to adult medicine. Eighteen 13 to 21 year-olds participated in focus groups, along with parents and providers and were presented with questions pertaining to their perception of the move to adult medicine. Aldiss (2015) showed that while providers were unable to perceive difficnlty in transitioning, parents and participants identified many changes to be made to improve the transition including preparation, education, and contact information.

\section{Transition Readiness}

Patient readiness to transition to adult medicine was the focus of a study by McManus et al., (2014). Four hundred and forty-five low-income Medicaid- 
enrolled patients aged 14-24 from five large pediatric, adolescent, and family medicine primary care clinics in Washington D.C. were the focus of a two-year comparative study. This quality improvement (QI) study used training tools for all staff at five facilities using the Health Care Index with six core readiness elements: policy, knowledge, registry, preparation, planning, and transfer. Comparative analysis of the transition index was done at three intervals throughout the study. Over the period of the study, a significant improvement to planned readiness and ease of transition was documented by staff after the implementation of the tool that involved health care workers walking each individual teen through a six-step process. Significantly improved confidence was shown by patients after staff members initiated their new program (McManus, 2014).

Transition readiness was also assessed by Beal, Ny, Marraccini, \& Biro (2014) using a convenience sample of 40 participants aged 12-21 at a freestanding Teen Health Center in a Midwestern city. Healthy participants were recruited through clinic flyers and given a 41-question survey. Some patients received cognitive interviewing while others only reeeived the survey. Beal et al, 2014 ) found that results indicated most of the teens had not even thought about the transition to another provider and had a lack of confidence they would be able to do so. Older participants did show more confidence. A wide age range gives strength to this study while reduced diversity due to the use of only one site was a limitation.

\section{Children with chronic conditions}

To better understand the reasons that adolescents do not follow through with health care after they turn 18 years, Kay, Rapley, Babel \& Brown (2013) examined the risk assessment of emerging adults as they transitioned to adult care. 
They conducted a two-year prospective cohort study with 53 patients with Diabetic Mellitus 1 (DM) age 17-19 years, at a large metropolitan teaching hospital. Data was collected using Hemoglobin AIC levels (HbAlC) and 4 well proven Diabetic questionnaires (PAID), (DES), (HADS, (EAT) at the inception of the study and 3 subsequent visits over 12 months. Results indicate the initial risk assessment at the first visit most predictive indicator of non-compliance with regards to the number of visits where those children with the highest anxiety and depression while, gender, race, and age were not significant factors. Depression and anxiety were found to be the significant factor in failed appointments and noncompliance leading to elevated $\mathrm{HbA} 1 \mathrm{c}$ levels. Individuals attending meetings and had closer follow-up had improved behavior and diabetic numbers.

Maturo et al., (2015) used 38 participants to conduct a retrospective study of teens with Human Immunodeficiency Virus (HIV) transitioning to adult medicine enrolled in the "Movin Out" program. The "Movin Out" program helps teens with HIV transition to adult medicine. All participants were from an HIV clinic, $15.8 \%$ of the participants had acquired immunodeficiency syndrome (AIDS) and $84.2 \%$ had HIV infection. Authors found that participants completing the five-phase program at one year out were stable and confident in their ability to manage their health care.

\section{Healthcare communication}

Parent and teen preferential use of communication with health care providers was examined by Rand, Blumkin, Vincelli, Katsetos, \& Szilagyi (2015) in a quantitative cross-sectional study of 400 random participants aged 10-17 years and their parents in Rochester, New York in 2011. Four pediatric clinics (2 suburban and 2 urban) were used to distribute a one-time flyer to patients to obtain demographic, race, age educational level, technology access and usage as well as 
their preferred method of communicating with their health care provider when health prevention reminders need to be sent out. Bivariate analysis was used to assess factors associated preferences for text versus email as preferred methods of communication. With multiple modes of communication available to all participants, results suggested that younger patients preferred text messaging while their parents preferred email.

In a large study in an out-patient clinic in 2013, Ahlers-Schmidt, Jones, Chesser, \& Weeks found that preferred methods of communication between healthcare providers and patients have evolved over time. While telephone communication was still the primary preference for aging patients, parents of pediatric patients preferred email appointment confirmation and health promotion and prevention information. Differing from their parents, teens identified texting was their preferred method of communication regardless of the nature of the information.

Rempel et al,, (2014) studied the effectiveness of text messaging to improve communication between health caregivers and patients. In a qualitative study in the Cardiology Division of the Stollery Children's Hospital in Canada, 13 participants aged 15-17 were recruited from a previous study of 24 congenital heart disease (CHD) patients. Patients with the technological capabilities of text messaging were recruited and nurses conversed with participants regarding their care. Field notes were coded into categories and subcategories and a qualitative inductive content analysis was performed on each texting interaction. Results showed that interaction through text messaging improved communication between nurses and patients. Texting as a preferred method of communication of teens is the strength of this study. The inability to analyze the non-uniformity of the communications between subject and nurse along with the fact that the subjects in 
this study were recruited from another study solely due to their condition provides the limitations.

In a systematic review of studies in 2013 , Yonkers found that incorporating familiar ways of communicating: preventative healthcare applications, email, text, and video visit lead to improved interaction between transitioning teens, their providers, and the healthcare industry. Yonkers promotes thinking outside the box when it comes to connecting with transitioning teens.

\section{Summary of Literature Review}

The literature review demonstrates that many factors affect the teen's experience in the transition to adult medicine. Providers who planned early supportive education surrounding transition and used technology, improved selfperceived confidence levels of teens and parents by encouraging them to begin to connect electronically with their provider. Proper assessment and adequate preparation were shown to be factors in improving adult medicine outcomes for teens to transition smoothly. Research also indicated that pediatric health care providers should begin readiness preparedness as early as mid-teens. 


\section{CHAPTER 3: METHODOLOGY}

\section{Setting}

The setting for this project was a large (500 patients per day) primary care pediatric outpatient clinic located in Santa Clara, CA, Two-thirds of the patients seen each day are under the age of ten with approximately one-tenth aged 17 years-old (Kaiser Santa Clara, 2017). Inclusion for participating in this project was defined as random 17 -year-old teens who were not currently connected online through the organization's email site and who were without chronic conditions. For the purposes of the project "without chronic conditions" was determined to mean they had not seen a specialist within the last two years. Teens with chronic conditions were excluded from this project.

\section{Participants}

Institutional Research Board (IRB) approval by both the institution where the project was carried out and the school that supported it expended additional scrutiny due to the age of the participants. Considered a vulnerable population, individuals under the age of 18 years must have written parental consent to participate in any project in addition to the participants own written assent.

\section{Recruitment}

A convenience sample recruitment was done randomly as 17 -year-old teens without chronic conditions arrived for care in the pediatric outpatient clinic. Once parental consent was obtained, participants were given assent forms and demographic contact information was retrieved, including EMR number, telephone number as well as personal email information (Appendix A). Fifty-four participants were initially enrolled in the qualitative project ( 33 females and 21 males). Each participant was given a two-digit identifier that was only associated with their Medical Record Number (MRN). 


\section{Project}

This project involved a series of five emails initially using the teen's private email then transitioning to the organization's email system. The first and last emails held duplicate pre-and post- instructional 10 question surveys (Appendix B) evaluating the teen's confidence in contacting their current health care provider. Emails in-between provided basic instructions for the teen in how to establish a secure message connection to the organization and their pediatric provider, and what to say once they did (Appendix C \& D). Upon completion, teens were encouraged to send an email to their pediatric provider to let them know they had successfully established an electronic connection (Appendix E). Finally, an email was sent that let the participant know that the provider had identified that they had contacted them (Appendix F), and a chart review of the participants EMR was conducted to determine if the teen completed the task. Upon task completion, a $\$ 5.00$ gift card was issued.

Forty-nine teens responded to the initial survey. Future email responses with instructions on how to connect to the organization's email system and what to say to their providers once they had accomplished that task. Twenty-one (38.8\%) of enrolled participants (14 female and 7 males) completed the last survey (Appendix B) and a chart view was done to ensure that their online connection with their pediatric provide was in fact established. 


\section{CHAPTER 4: RESULTS}

Fifty-four participants were initially enrolled in the project ( 33 females and 21 males). Each was sent an initial email which included a short 10 question survey. Forty-nine teens responded to the initial survey monkey while only Twenty-one (38.8\%) of enrolled participants ( 14 female and 7 males) completed the last survey and a chart view was done to ensure that their online connection with their pediatric provider was in fact established. Figure 1 demonstrates by gender, the attrition rate over the course of the project.

Project Participation
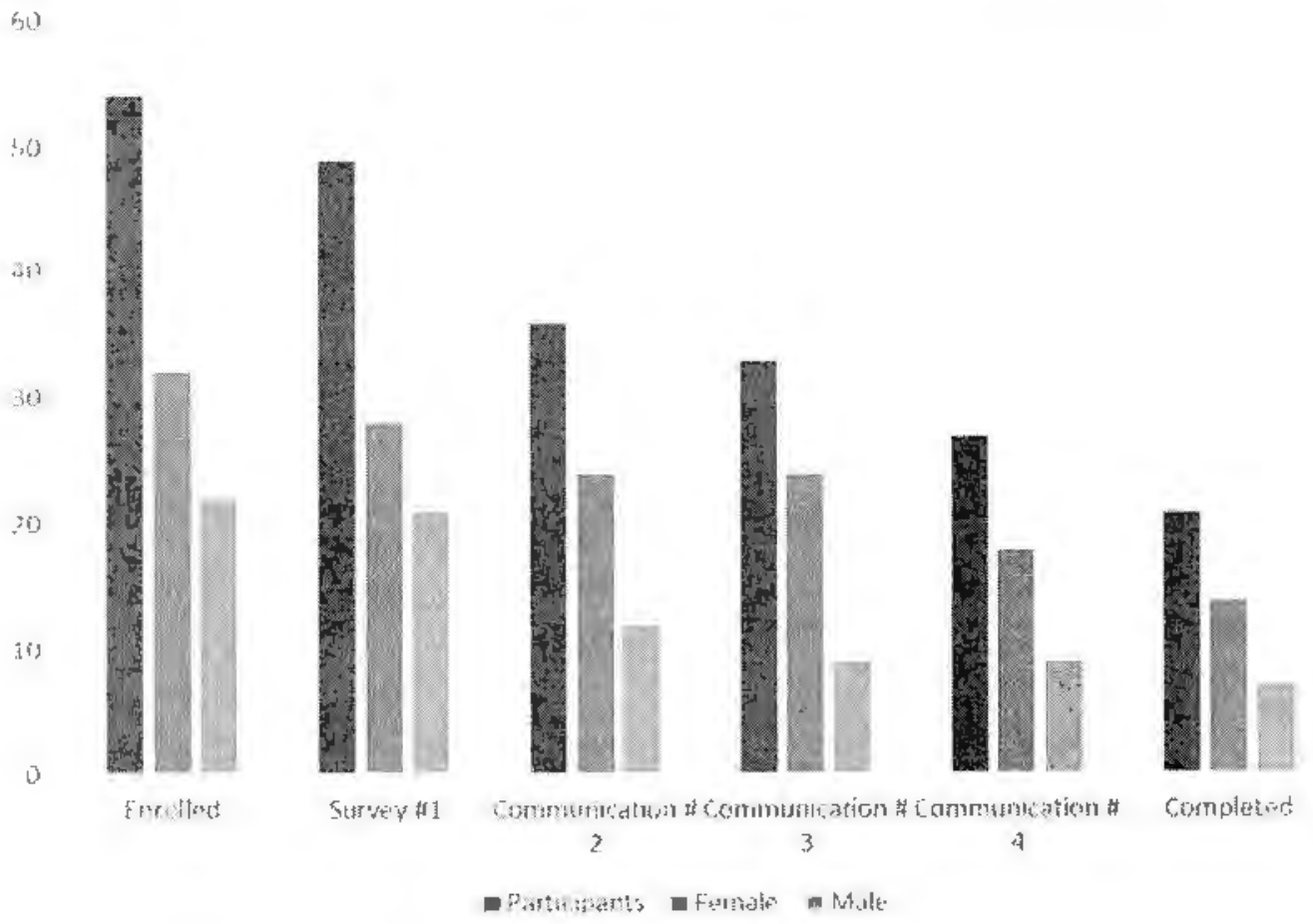

Figure 1. Project participation by gender 
Results of the survey showed that five $(10.2 \%)$ of the initial respondents felt somewhat confident in contacting their health care provider or booking themselves an appointment (Figure 2). Succeeding emails provided participants with instructions on how to connect to the organization's email system, what to say to their provider once they established the connection as well as examples of what should be withheld from email conversations due to privacy issues.

Responses to emails began to drop off steadily after the second email was sent. Twenty-one (38.8\%) of enrolled participants (14 female and 7 males) completed the last survey and a chart view was done to ensure that their online connection with their pediatric provide was in fact established. Figure 3., depicts the final survey that demonstrates that 17 of the 21 final respondents $(80.9 \%)$ felt at least moderately confident in their ability to communicate with their pediatric provider and book themselves an appointment through the organization's email system.

Initial Survey Confidence

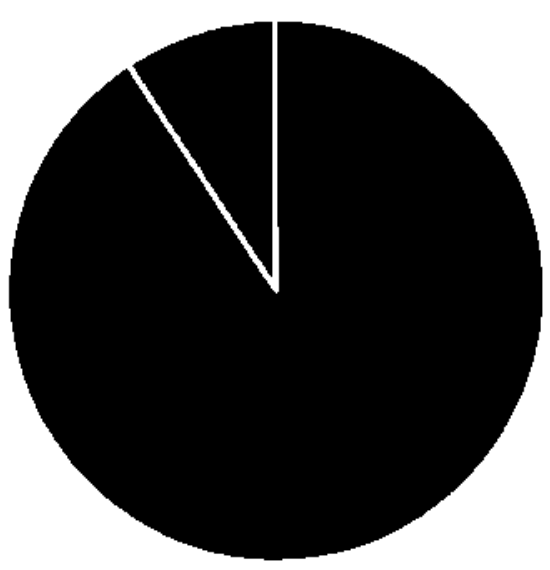

- < Moderate Confidence - > Moderate Confidence

Figure 2. Initial survey for confidence. 


\section{Final Survey Confidence}

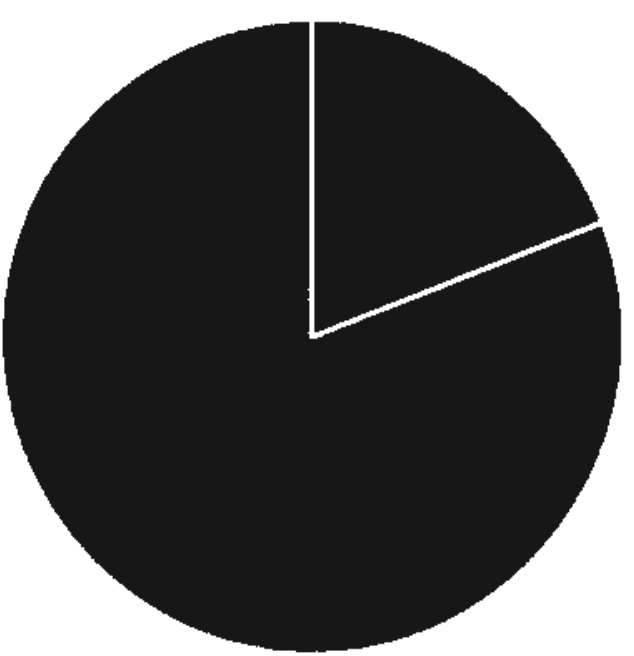

- Moderate Confidence "s Moderate Confidence

Figure 3. Final survey for confidence. 


\section{CHAPTER 5: CONCLUSIONS AND RECOMMENDATIONS}

This project demonstrated that teen confidence in their ability to interact with medical personnel was increased with the knowledge and skills that was provided. In support of McManus, (2014) findings, participants were noted to have improved communication with providers with an intervention to transition program which also improved long term outcomes. Recommendations from this project include but are not limited to: connecting earlier with teens, reducing the interactions with teens, and supporting provider-driven communication through email regarding the impending transition process.

\section{Early Intervention}

Starting the process of establishing a digital connection between pediatric providers and their teen population earlier than 17 , in preparation for their transition is crucial because many of them are not seen by their provider between 17 and 18 years of age. In alignment with Beal, Ny, Marraccini, \& Biro (2014) study on transition readiness, moving forward, fifteen and sixteen-year-old patients should be approacbed and encouraged to become connected online with their so that they are not lost in the system.

\section{Condensing Educational Component}

Extensive emails possible drove attrition rate high in this project. Recommendations to shorten and simplifying instructions and limit the number of communications with adolescents may improve completion rates in further studies. Limiting clear, age-appropriate instructions through 2 emails or texts may improve participation in future projects with teens. Ideally, rapid use of clinic office time to physically belp teens to connect digitally would be the ultimate solution to improving communication between teens and their pediatric provider. 


\section{Provider Driven Communication}

Online communication with teens appears to be vitally important to continuing continuity of care. Once teens are digitally connected with their pediatric provider, health care representative from all areas within a healthcare system can engage with the emerging adults. At this facility, this connection has proven beneficial to both patients and providers in improving health prevention and promotion and preparation for their impending transition to adult medicine.

\section{Future Studies}

Utilizing information gathered from this QI project, future research involving emerging adults, healthcare and technology is necessary to help improve long-term health outcomes. Is the use of emergency services higher in emerging adults who not connected to a provider? Are Healtheare Effectiveness Data Information Sets (HEDIS) measures improved in emerging adults who are connected to a personal care provider? If available from the organization, would the use of texting improve communication between provider and emerging adult?

Twenty-first-century healthcare utilizes technology in a multitude of facets. Using the latest and most up-to-date technology available, health care organizations, providers, and their representatives that think outside the box are more likely to improve the quality of care they provide to their patients. 
REFERENCES 


\section{REFERENCES}

Ahlers-Schmidt, C., Jones, J., Chesser, A., \& Weeks, K. (2013). Evaluating opportunities for text message communication: A survey of parents and teens. Telemedicine Journal and E-health: The Official Journal of the American Telemedicine Association, 19(9), 711. Retrieved from: http://www.liebertpub.com/tmj

Aldiss, S., Ellis, J., Cass., Pettigrew, T., Rose, L., \& Gibson, F. (2015). Transition from child to adult care- it's not a one-off event: Development of benchmarks to improve the experience. DOI: http://dx.doi.org/10.1016/j.pedn.2015.05.020

Arnett, J. (2003). "Emerging adulthood. A theory of development from the late teens through the twenties." The American Psychologist 55.5 (2000):469-80. Retrieved from http://www. http://sfx.calstate.edu:9003/fresno

Bandura, A., \& Estes, W. (1977). Self-efficacy: Toward a unifying theory of behavioral change. Psychological Review, 8(2), 191-215.

Beal, S., Nye, A., Marraccini, A., \& Biro, F. (2014). Evaluation of readiness to transfer to adult healthcare: what about the well adolescent? Health Care: The Journal of Delivery Science and Innovation, 2(4), 225-231. DOI: 10.1016/j.hjdsi.2014.10.001

Braungart, M., \& Braungart R., (2011). Educational and learning theories. In J. B. Butts, \& K.L. Rich (Eds.). Philosophies and Theories for Advanced Nursing Practice (pp.195-234), Burlington, MA: Jones \& Bartlett. 
Brooks, M., Bear, T., Hacker, K., Foulds, A., \& Miller, E., (2105). Healthy Allegheny teens survey: a model for county-wide survey-based research. Journal of Adolescent Health, 56(2), S47-S48. doi.org/10.1016/j

Cohn, A., Hunter-Reel, D., Hagman, B. \& Mitchell, J. (2011). Promotion behavior from alcohol use through mobile technology: the future of ecological momentary assessment. Alcoholism: Clinical and Experimental Research, 35 (12), 2209-2215. Http://doi:10.1111/j.1530-0277.2011.01571

English, A., Ford, C., (2014). The HIPPA privacy Rule and adolescents: legal questions and clinical challenges. The Guttmacher Institute 36(2). DOI: https://doi.org/10.1363/3608004

Fugard, A., \& Potts, H., (2015). Supporting thinking on sample sizes for thematic analyses: a quantitative tool. International Journal of Social Research Methodology 18(6), pp. 669-684. http://dx.doi.org/10.1080/13645579.2015.1005453

Haggerty, K., Fleming, C., Catalano, R., Harachi, T., \& Abbot, R., (2006). Raising healthy children: examining the impact of promoting healthy driving behavior within a social development intervention. Prevention Science, 7(257). Http://doi:10.1007/s11121-006-0033-6

Journal of Adolescent Health (2017). Author information pack. Journal of Adolescent Health: Society for Adolescent Health and Medicine. Retrieved at: https://www.jaholine.org.

Kaiser (2017). Pediatric dashboard. Santa Clara Kaiser Permanente: 2016 Annual Report. 
Kaiser (2017). Division of Research: Institutional review board. Retrieved from: https://dor.kaiser.org/external/DORExternal/research/irb.aspx

Maturo, D., Powell, A., Major-Wilson, H., Sanchez, K., Santis, D., \& Friedman, L. (2015). Transitioning adolescents and young adults with HIV infections to adult care: Pilot testing the "Movin' Out" transitioning protocol. Journal of Pediatric Nursing, 30(5), e29-e35. Retrieved from: https://doiorg.hmlproxy.lib.csufresno.edu/10.1016/j.pedn.2015.06.013.

Mcmanus, M., White, P., Barbour, A., Downing, B. \& Hawkins, K. (2015). Pediatric to adult transition: A quality improvement model for primary care. Journal of Adolescent Health, 56(1), 73-78. http://dx.doi.org.hmlproxy.lib.csufresno.edu/10.1016/j.jadohealth.2014.08.006

Melnyk, B. \& Fineout-Overholt, E. (2014). Evidence-based practice in nursing and healtheare: A guide to best practice, (3rd ed.). Kindle Edition.

National Institute of Health (2016). Research using vulnerable populations: Children.Retrieved from: https://grants.nih.gov.

Rand, C., Blumkin, A., Vincelli, P., Katsetos, V., \& Szilagyi, P. (2015). Parent preferences for communicating with their adolescent's provider using new technologies. Journal of Adolescent Health, 57(3), 299-304. Http://doi: 10.1016

Rempel, G. Ballantyne, T., Magill-Evans, J., Nicholas, D, Mackie, A. (20140. Texting teens in transition: the use of text messages in clinical intervention research. Journal of Medical Internet Research Mhealth and Uhealth, 2(4). doi: $10.2196 /$ mhealth. 3232 
Sawicki, G., Garvey, K., Toomey, S., Williams, K., Hargraves, J., James, T., Raphael, J., Giardino, A., Schuster, M., Finkelstein, J., (2017). Preparation for transition to adult care among medicaid-insured adolescents. Pediatrics, 140(1). https://doiorg/10.1542.peds.2016-2768

Shields, L., \& Pearn, J. (2007). Inducements for medical and health research: Issues for the profession of nursing. Journal of Clinical Nursing, 16(7), 1196-1200. Http://Doi:10.1111/j.1365-2702.2007.01889

Smith, K., Macias, K., \& Betz, C. (2015). Brief report: Adolescents' reasons for participating in a health care transition intervention study. Journal of Pediatric Nursing, 30(5), 165-171. Http:/Doi:101016/j.pedn.2015.05.007.

Smith, S., Morgan, S., \& Riley, V. (2010). Priorities and challenges in the care of teenagers and young adults. Cancer Nursing Practice 10(1), 32-38. http://dx.doi.org/10.7748/cnp2011.02.10.1.32.c8334.

Steefel, L. \& Saver, C. (2013). From capstone project to published article. American Nurse Today, 8(5). Retrieved from: https://www.americannursetoday.com. 


\section{APPENDICES}


APPENDIX A: PARTICIPANT FLYER 


\section{Connecting Transitioning Teens with their Healthcare Providers}

On your $18^{\text {th }}$ birthday, you will become an adult and will be transferred out of the pediatric clinic and into the internal medicine department (where your parents receive their healthcare). To ease your transition to internal medicine at 18 , I have developed an online tool that I would like your participation in a trial of. The aim is to help you, help yourself navigate your healthcare at Kaiser Permanente.

Your participation in this project will involve receiving an online survey via the email you provide below. Once you have completed the survey you will be sent an additional email with information regarding accessing KP.org and the KP MyDoctorOnline app, along with additional age-appropriate healthcare information. After completing the tool, the final survey will be sent to you using your new KP.org account. You will then send an email to your provider and they will respond to you.

After two short online surveys and completion of a task, you will be given your choice of a $\$ 5.00$ iTunes or Starbuck's gift card for your participation.

If you choose to participate in this project, your signature along with your parent's signature to consent to participate will be required (a separate page).

You can withdraw from this project at any time for any reason.

I have read the above information regarding this project and understand that my participation is voluntary (circle one) YES / NO

Participant Printed Name and signature: l

Parental Name and Signature:

Medical Record number:

Personal email address:

Cell phone number:

Kathv.A.Prows@kp.org. For questions or concerns please phone 408-851-1121 


\section{APPENDIX B: PARTICIPANT EMAIL \#1}




\section{Survey Invitation}

\section{Dear Participant \#}

Thank you for participating in this project. Please use the attached link to complete this short "Teen Survey".

https://www.surveymonkey.com/r/9DBSH8L

Once you have completed the survey, please contact me at

Kathy.A.Prows@kp.org to advise that you have completed it. Upon completion of the survey, I will send you specific information with Kaiser Permanente instructions on how to link yourself to your Kaiser provider through KP.org and MyDoctorOnline and what that enables you to do.

After successfully signing up for KP.org and the MyDoctorOnline App, we will communicate through KP.org. I will then have you send an email to your pediatric provider. Your pediatric provider will then respond to your email to confirm the connection has been made.

The final piece of this project will be that you complete one last survey that will be sent to you at your new KP.org account.

Thank you,

Kathy Prows, MSN, RN- Project Investigator Pediatric Department Santa Clara Kaiser Permanente Kathy.A.Prows@kp.org 
APPENDIX C: PARTICIPANT EMAIL \#2 


\section{Teen Survey}

What is your gender?

0 Male

0 Female

0 Trans or intergender

Do you understand that after you turn 18 years old you will no longer see your current pediatric provider (doctor or nurse practitioner)?

0 Yes

$0 \mathrm{No}$

0 Not sure what this means

Have you ever made an appointment BY yourself FOR yourself to see a provider (doctor or nurse practitioner) at Kaiser?

0 Y e s

$0 \mathrm{No}$

Are you aware that you can choose your adult medicine provider (doctor or NP)?

0 Y e s

$0 \mathrm{No}$

0 Not sure what this means

If you are female, have you selected a women's health/gynecologist?

$0 \mathrm{No}$

0 Not Applicable

Do you own a smartphone or computer?

Smart Phone

Yes

Computer

0

Other

0

0

No

0

0

0 
Are you aware that there are 4 ways to contact your doctor or nurse practitioner? Email, video visit, text, in-person appointment.

0 Yes

$0 \mathrm{No}$

Have you ever emailed, texted, or used KP online to contact your current provider (doctor or nurse practitioner)? Or ordered a medication refill online?

$\begin{array}{llcc} & \text { Yes } & \text { No } & \text { Not sure } \\ \text { Emailed } & \text { C. } & 0 & 0 \\ \text { Texted } & 0 & 0 & 0 \\ \text { Used KP online } & 0 & 0 & 0 \\ \text { Video visit for example } & 0 & 0 & 0 \\ \text { Skype } & 0 & 0 & 0 \\ \text { Medication refill only } & & & \end{array}$

Do you have any KP 'app' downloaded on your smartphone?

0 Yes

$0 \mathrm{No}$

Maybe

How confident are you right now with your ability to manage your own health care needs?

0 Not at all confident

0 Slightly confident

0 Moderately confident

0 Highly con fident

0 Not sure what this means 


\section{APPENDIX D: PARTICIPANT EMAIL \#3}




\section{Instructions for signing up for KP.org and My Doctor Online}

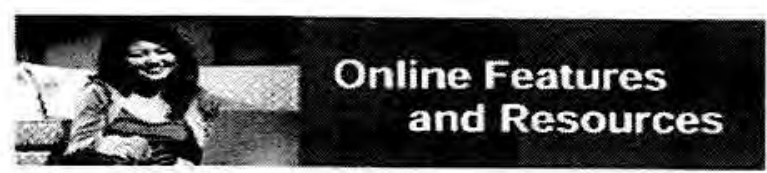

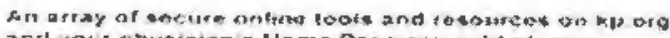

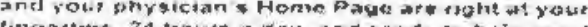

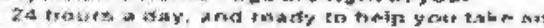

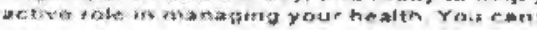

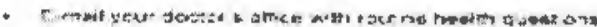

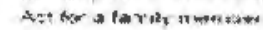

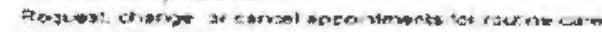

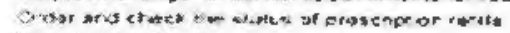

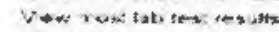

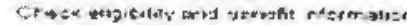

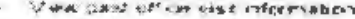

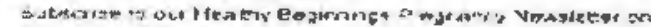

uporaimandoctor

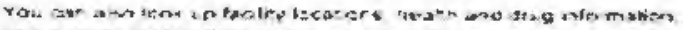

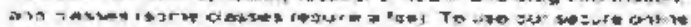
tat it

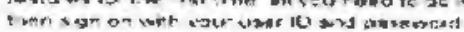

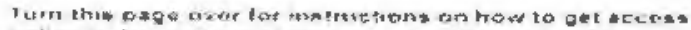

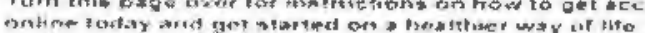

H. kaISER PERMANente.

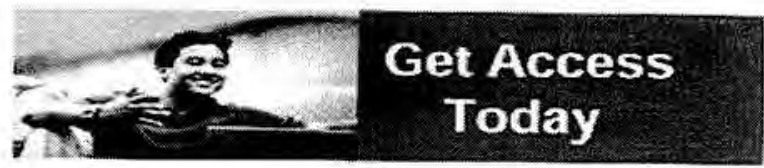

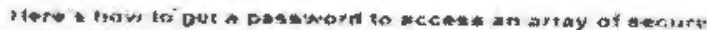

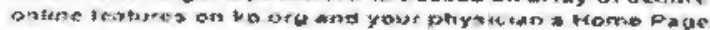

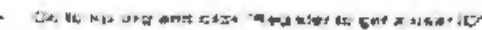

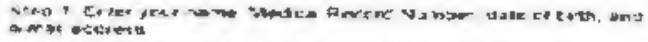

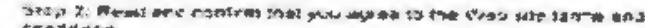
rengerente

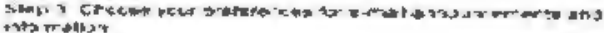

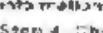

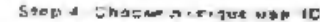

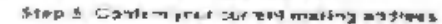

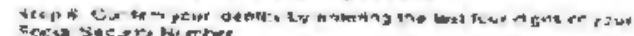

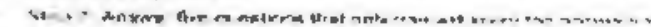

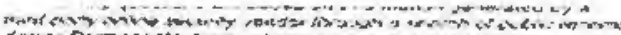

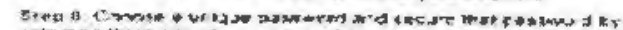

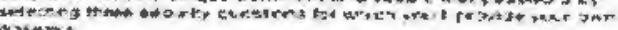

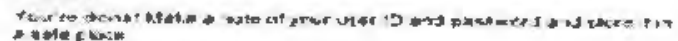

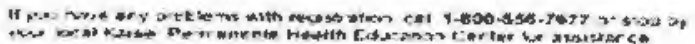

HA KAISER PERMANENTE. 

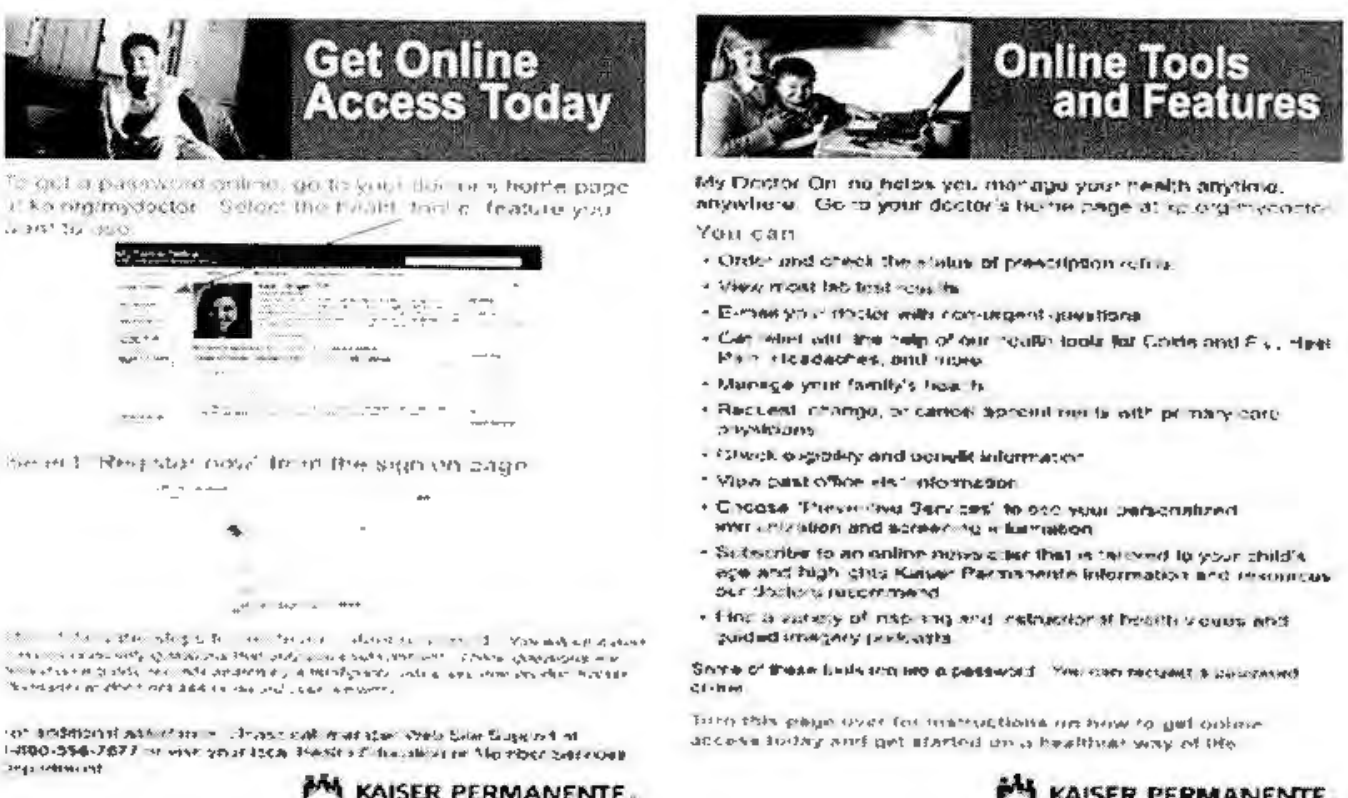

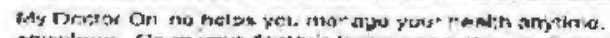

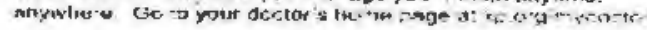
Yon can

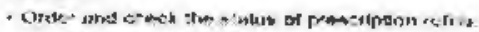

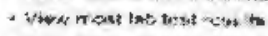

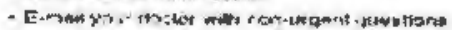

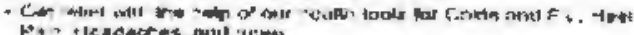

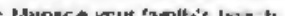

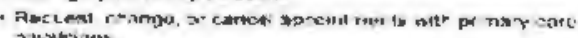

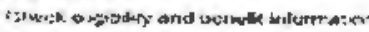

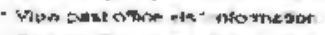

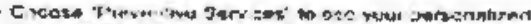

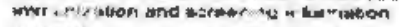

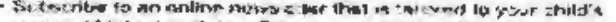

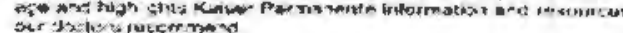

(1)

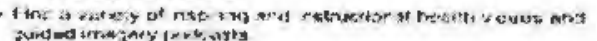

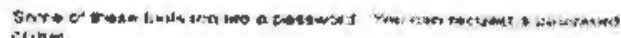

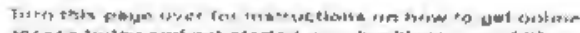

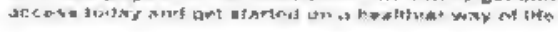

MH KAISER PERMANENTE

M KAISER PERMANENTE. 
APPENDIX E: PARTICIPANT EMAIL \#4 


\section{Emailing Guideline for teens}

Congratulations on signing up for KP.org! You are now connected to your healthcare world at

Kaiser Permanente. I would like you to send an email to your provider@PCP@ to say hello and let them know that they can contact you through KP.org with any messages they might have regarding your health. Once you do that your provider will email you back to welcome you to KP.org and they will let me know that they heard from you! An example of a simple email for you to send would be.

"Hi Dr. this is (your name). I just wanted to let you know that I am now active on KP.org and if you need to reach me you can email me. My contact phone number is

Thank you, (your name)"

Once you have sent the email to your provider and your provider lets me know, you have done so, I will send you a short final survey through KP.org for you to complete. Send me a secure message through kp.org to let me know you have completed the survey and whether you want a $\$ 5.00$ iTunes or Starbucks card and the address where I should send it.

Welcome to Kp.org and many health connections!

Kathy Prows, MSN, RN- Project Investigator

Pediatric Department

Santa Clara Kaiser Permanente

Kathy.A.Prows@kp.org 
APPENDIX F: PARTICIPANT EMAIL \#5 


\section{Final Survey}

Hello,

Dr. let me know that they received your email through $\underline{\mathrm{KP} . o r g}$. Great work! Please complete the following survey now that you have linked yourself with your health care provider and Kaiser Permanente.

https://www.surveymonkey.com/r/9DBSH8L

Please respond to this email which will go directly to me once you have completed the final survey. Please indicate which gift card you would like and which address it should be mailed to. Please allow 2-3 weeks for the gift card to arrive in the United States Mail.

Thank you for your participation in this project.

If there is anything you need or have questions, feel free to reach out through KP.org to your provider or myself at any time. Once again, please do not leave urgent messages on KP.org use the Kaiser Call Center for those at 408-554-9810.

Best of health!

Kathy Prows, MSN, RN- Project Investigator Pediatric Department Santa Clara Kaiser Permanente Kathy.A.Prows@kp.org 
APPENDIX G: INSTITUTIONAL REVIEW BOARD APPROVALS 


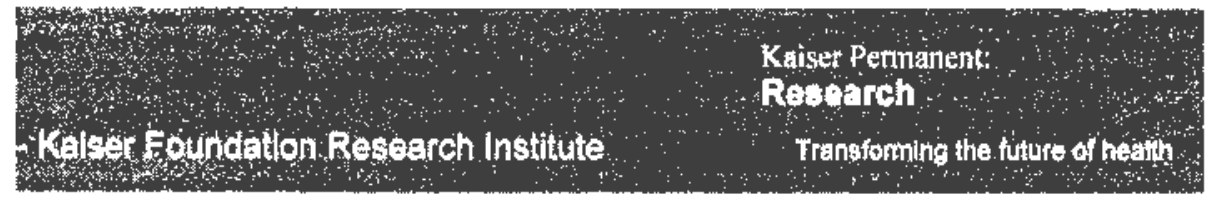

SulyicctTitle: Improving Teen and Pediatric Provider Communication Using Education and Technolog: RDOKPNC 17-82

Date: Oclober 18th. 2017

Dear Kathy Connol-P'rows:

Please see below datternination outcome and the atlached checklist used.

As the Research Deternination Ofticial (RDO) for the Kaiser Pennanente Northem Califomia region. I have rctieucd the documents submitted for the above-referenced project. The project does not meet the regulatory definition of research involving human subjects as noted here:

\section{Not Research}

The activity does nol meet the regulatory detinition of research per 45 CFR 46.102(d): A systemic inwestigation. including researtł development, testing and evaluation, designed to develop or coniribute to generalizable knowledge.

Nol Human Subject Rescarth

The activity does not meet the regulatory definition of rescarch involving buman subjects per 45 CFR 46. I02(1'): Human suhjects means a living individual about whom an investigator conducting research oblains (1) data through intervention or interaction with the individual. or (2) identifiable privale information.

Therefore. lhe project is not required to be reviewed by a KP Institutional Review Board (IRB). This determination is based on the intomation provided. If the scope or nature of the project changes in a manner that could impacl this teview. please resubmit for a new determination. Also. you are responsible tor keeping a copy of this determination feter in your project files as it may be necessary to demonstrate that your project was properly reviewed.
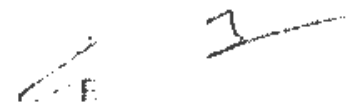

Provide this approval letter to the Pby sician in Charge (P[C) your Area Manager. and Chiel of Serviec, to determine whether additional approvals are needed.

Sincerely:

National Reseatch Compliance Oflicer

Dircetor. National Complinnce in Rescarch Support Program

Katiser Foundation Research Institute

$\$ 800$ Harrison Street

Stite 1600

Oakland. $C \wedge 94612$

$510-625-2397$ (telephone)

510-625-2330 (tax)

liric. E (iarcialalp.org) 


\section{MEMORANDUM}

Date: December 22, 2017

To: $\quad$ Ruth Rosenblum, Principal Investigator

Department of Nursing

From: thing Clarke/MK

Kris Clarke, Chair

Committee on the Protection of Human Subjects

\section{Protocol \#834: Improving Teen and Provider Communication using Education and Technology}

The Committee on the Protection of Human Subjects performed a full review of your project and approves of your project with the submitted revisions. Your project is approved with the addition of one further revision:

1. Please add language on the informed consent and assent forms (age appropriate) that indicates that the researcher is a mandated reporter, so that the subjects know that the researcher must report to authorities any suspected abuse, such as: "By law, the study team must release certain information to the appropriate authorities if at any time during the study there is concern that child abuse has possibly occurred or you disclose a desire to harm yourself or others." OR "We will keep your child's (your) study data as confidential as possible, except for certain information that we must report for legal or ethical reasons, such as child abuse or negleet."

Approval for your project expires December 22, 2018. Should your study last more than one year, please submit an annual renewal form found on our website. 
APPENDIX H: NIH CERTIFICATE 


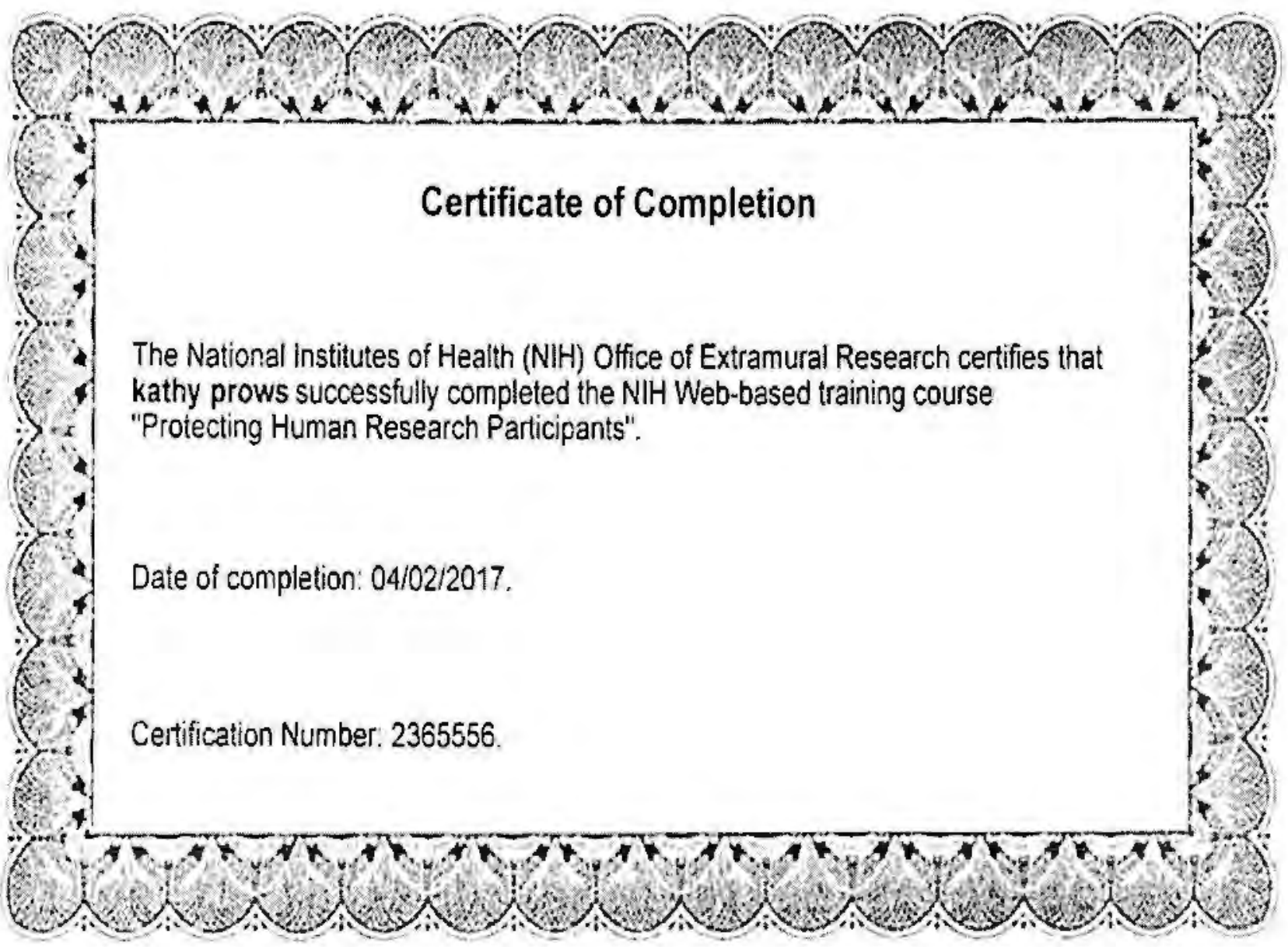

